\title{
Ventilation effects on humidity measurements in thermometer screens
}

Article

Accepted Version

Harrison, R. G. and Wood, C. R. (2012) Ventilation effects on humidity measurements in thermometer screens. Quarterly Journal of the Royal Meteorological Society, 138 (665). pp. 1114-1120. ISSN 1477-870X doi: https://doi.org/10.1002/qj.985 Available at https://centaur.reading.ac.uk/24582/

It is advisable to refer to the publisher's version if you intend to cite from the work. See Guidance on citing.

To link to this article DOI: http://dx.doi.org/10.1002/qj.985

Publisher: Royal Meteorological Society

Publisher statement: This is a preprint of an article accepted (November 2011) for publication in Quarterly Journal of the Royal Meteorological Society Copyright (C2011,2012 Royal Meteorological Society

All outputs in CentAUR are protected by Intellectual Property Rights law, including copyright law. Copyright and IPR is retained by the creators or other copyright holders. Terms and conditions for use of this material are defined in the End User Agreement.

www.reading.ac.uk/centaur 
Central Archive at the University of Reading

Reading's research outputs online 
R.G. Harrison ${ }^{\mathrm{a}^{*}}$ and C.R. Wood ${ }^{\mathrm{a}, \mathrm{b}}$

a Department of Meteorology, University of Reading, UK

b Finnish Meteorological Institute, PO Box 503, 00101 Helsinki, Finland

* Corresponding email: r.g.harrison@ reading.ac.uk

\begin{abstract}
Relative humidity (RH) measurements, as derived from wet-bulb and dry-bulb thermometers operated as a psychrometer within a thermometer screen, have limited accuracy because of natural ventilation variations. Standard RH calculations generally assume a fixed screen psychrometer coefficient, but this is too small during poor ventilation. By comparing a reference humidity probe-exposed within a screen containing a psychrometer - with wind-speed measurements under controlled conditions, a wind-speed correction for the screen psychrometer coefficient has been derived and applicable when 2-metre wind speeds fall below $3 \mathrm{~ms}^{-}$ 1. Applying this to hourly-averaged data reduced the mean moist RH bias of the psychrometer (over the reference probe) from $1.2 \%$ to $0.4 \%$, and reduced the inter-quartile range of the RH differences from $2.0 \%$ to $0.8 \%$. This correction is particularly amenable to automatic measurement systems.
\end{abstract}

Keywords: psychrometer; hygrometer; wet-bulb; automatic weather station; supercooling. 


\section{Introduction}

Determining long-term trends in surface meteorological quantities, such as relative humidity (RH), requires a consistent series of reliable and well-characterised measurements (Willett et al., 2007). Some surface humidity measurements are obtained using wet- and dry-bulb thermometers within a standard thermometer screen, i.e. together comprising a screen psychrometer. Whilst wet-bulb and dry-bulb temperatures of forceventilated psychrometers can readily be used to determine relative humidity, the performance of naturallyventilated screen psychrometers can be poor (WMO, 2006), with appreciable systematic uncertainty and variability at low wind speeds. Screen psychrometers form part of the UK's long-term monitoring network, hence their uncertainties will contribute uncertainty in any long-term humidity trend deduced from them. A small humidity trend is difficult to detect, but the UK Climate Impact Programme UKCP09 results suggest a relative humidity reduction of up to 5\% for England, Scotland and Wales between 1961 and 2006 (Murphy et al., 2009). The effect of screen psychrometer uncertainties on this long-term trend will depend on the prevalence of screen psychrometer data in the particular measurements analysed, and the ventilation circumstances of the instrumentation. Ventilation effects on psychrometers in general are considered further here through laboratory and field experiments, comparing screen psychrometer data with nearby reference humidity measurements.

Uncertainty in RH determined by a screen psychrometer arises from both limitations in the accuracy of the measured wet-bulb and dry-bulb temperatures, and the effect of screen ventilation. Ventilation affects the lag times of screen thermometers in terms of their ability to measure air temperature (Aitken, 1921; Harrison, 2010), but it also strongly affects the psychrometer coefficient needed in the calculation of RH. The ventilation of a psychrometer can be very poor, since the air speed measured within a screen is several times smaller than the wind speed conventionally observed outside it (Keil, 1996).

This is a preprint of an article accepted (November 2011) for publication in Quarterly Journal of the Royal Meteorological Society Copyright @2011,2012 Royal 
For a screen psychrometer determining wet-bulb temperature $\left(T_{\text {wet }}\right)$ and dry-bulb temperature $\left(T_{\text {dry }}\right)$, the $\mathrm{RH}$ is found by first determining the vapour pressure $e$

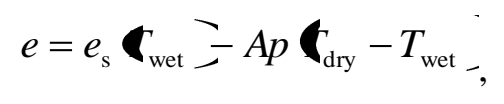

and then calculating the $\mathrm{RH}$ from

$$
R H=\frac{e}{e_{\mathrm{s}} \boldsymbol{d}_{\mathrm{dry}}} \times 100 \%
$$

where $A$ is the psychrometer coefficient, $p$ the atmospheric pressure and $e_{\mathrm{s}}(T)$ the saturation vapour pressure of water at temperature $T$. For calculations, $e_{\mathrm{s}}(T)$ is conveniently approximated (to better than $0.5 \%$ over the range $\pm 40^{\circ} \mathrm{C}$ ) by

$$
e_{\mathrm{s}}(T)=6.112 \exp \left(\frac{17.67 T}{T+243.5}\right)
$$

for $T$ in ${ }^{\circ}$ Celsius (Bolton, 1980). The standard constant value of $A$ assumed for a screen psychrometer is $0.8 \times 10^{-3} \mathrm{~K}^{-1}$, which neglects the wind-speed dependence and any particular geometrical aspects of the thermometers used (HMSO, 1982).

By combining Equations (1) to (3), the sensitivity of the derived RH to uncertainties in $T$ and $A$ can be evaluated. Figure 1 shows the results of such calculations, firstly (Figure 1a and 1b) allowing the wet-bulb depression $\left(T_{\text {dry }}-T_{\text {wet }}\right)$ to vary by $\pm 0.2^{\circ} \mathrm{C}$ to represent uncertainties in both the $T_{\text {dry }}$ and $T_{\text {wet }}$ temperature measurements (but neglecting the effect of $T_{\mathrm{dry}}$ and $T_{\text {wet }}$ on their associated $e_{\mathrm{s}}$ ), and, secondly (Figure 1c and 1d), by varying $A$ between $0.7 \times 10^{-3} \mathrm{~K}^{-1}$ and $1.1 \times 10^{-3} \mathrm{~K}^{-1}$ to represent the increase in $A$ associated with reducing wind speed (HMSO, 1982). The differences in RH arising from the temperature uncertainties lie mostly below $8 \%$, but are greatest at low temperatures and small wet-bulb depression (high humidity); the effect of variations in $A$ on $\mathrm{RH}$ is much greater, typically 5-20\% and greatest during colder and drier This is a preprint of an article accepted (November 2011) for publication in Quarterly Journal of the Royal Meteorological Society Copyright @2011,2012 Royal Meteorological Society 
circumstances. Such uncertainties in RH would clearly be substantially greater than long-term RH trends derived from the UK surface data, although it is not clear to what extent screen psychrometers contributed to the Murphy et al. (2009) analysis. Since the ventilation-dependent uncertainties in RH vary systematically with wind speed they will not, unlike random errors, be removed by averaging.

The psychrometer ventilation effect has been investigated experimentally under laboratory and controlled field conditions respectively (section 2, with results in section 3), and the ventilation speed variation of the screen psychrometer coefficient derived was compared with measurements made at an independent climatological station (section 4).

\section{Experimental investigations of psychrometer ventilation effect}

\section{(a) Laboratory experiment}

Using a laboratory experiment, the effect of air speed on a psychrometer under controlled conditions was investigated, within a wind tunnel into which ambient laboratory air was drawn by an adjustable electric fan. Two electrical resistance (thermistor) thermometers were mounted within the tunnel, one of which was operated as a wet bulb using distilled water and a muslin wick (Figure 2). The thermistor thermometers determined $T_{\text {dry }}$ and $T_{\text {wet }}$ for the inflowing air; before and after the experiments, they were each bias corrected against a Digitron T600 precision thermometer (to $\pm 0.1 \mathrm{~K}$ ). As well as the psychrometer temperatures, the air's dew-point temperature $\left(T_{\mathrm{dew}}\right)$ was measured (to $\pm 0.1 \mathrm{~K}$ ) and the air speed $U$ downstream of the thermometers recorded (to $\pm 0.1 \mathrm{~ms}^{-1}$ ).

During the experiment, the air speed was varied in the range $0-3 \mathrm{~ms}^{-1}$. Readings of $T_{\mathrm{dew}}, T_{\mathrm{dry}}$ and $T_{\text {wet }}$ were taken at each air speed, waiting (up to ten minutes at $0 \mathrm{~ms}^{-1}$ ) to ensure that the readings were stable. The experiment was repeated on three different days, to broaden the range of absolute humidity and temperature data obtained.

This is a preprint of an article accepted (November 2011) for publication in Quarterly Journal of the Royal Meteorological Society Copyright @2011,2012 Royal Meteorological Society 
The field experiment extended the investigation of an idealised laboratory psychrometer to an atmospheric psychrometer operating within a large thermometer screen. $\mathrm{RH}$ measurements, as derived from the psychrometer, were compared with reference measurements determined by a Vaisala HMP45A capacitative humidity probe operated within the same screen at the University of Reading's Atmospheric Observatory ${ }^{1}$. The thermometers used within the screen were $5 \mathrm{~mm}$-diameter cylindrical platinum resistance thermometers (PRTs), conforming to the BS1904 (Class B) Pt100 standard in calibration and linearity, with one operated as a wet-bulb. These had previously been calibrated against the Meteorology Department's precision reference thermometer (Automatic Systems model F250) on $3^{\text {rd }}$ February 2010 before their installation in the screen, after which they were monitored daily by the Meteorological Observer. Both the PRTs were used with precision resistance-to-voltage convertors (Harrison and Rogers, 2006). Atmospheric pressure was measured using a Druck DP141 precision barometer (which operates on the vibrating drum principle). Voltages derived from the resistance thermometers, barometer and the humidity probe were sampled synchronously at 1-second intervals, at 12-bit resolution. The accuracy of the HMP45A humidity reference probe is quoted by the manufacturer as $\pm 1 \%$ against factory references at $20^{\circ} \mathrm{C}$, and $\pm 2 \%$ in field-use for $\mathrm{RH}<90 \%$, with a drift of less than $1 \%$ annually. The accuracy of the probe is therefore better than the typical ventilation-induced uncertainty in RH derived from the screen psychrometer (Figure 1).

Because of lag times of many minutes or longer for large thermometer screens at low wind speeds (Harrison, 2011), hourly-average values were computed from the electrical thermometers and relative-humidity probe. These hourly average values of the $T_{\text {dry }}$ and $T_{\text {wet }}$ temperatures and pressure were used to determine the screen psychrometer $\mathrm{RH}\left(R H_{\mathrm{p}}\right)$, for comparison with the reference probe $\mathrm{RH}\left(R H_{\mathrm{r}}\right)$. The wind-speed measurements were made using a cup anemometer mounted close to the screen at 2 metres above the ground (Vector instruments A100, starting speed of $\sim 0.2 \mathrm{~ms}^{-1}$ ).

\footnotetext{
${ }^{1}$ http://www.met.reading.ac.uk/Data/fieldsite/
}

This is a preprint of an article accepted (November 2011) for publication in Quarterly Journal of the Royal Meteorological Society Copyright @2011,2012 Royal Meteorological Society 


\section{Results}

The ventilation variation effects on the psychrometer coefficient in the laboratory and screen cases are now analysed and compared.

\section{(a) Laboratory experiment}

From the series of measurements obtained (of $T_{\text {wet }}, T_{\text {dry }}, p$ and $T_{\text {dew }}$ ) for different wind speeds, the psychrometer coefficient $A_{\text {eff }}$ was determined by rearranging Equations (1) and (2) as

$$
A_{\text {eff }}=\frac{e_{\mathrm{s}} \boldsymbol{\Upsilon}_{\mathrm{wet}}-e}{p \boldsymbol{\bigotimes}_{\mathrm{dry}}-T_{\mathrm{wet}}},
$$

where $e=e_{\mathrm{s}}\left(T_{\mathrm{dew}}\right)$. These values were plotted against the measured air speed to show the relationship between ventilation $u$ and psychrometer coefficient $A_{\text {eff }}$ (Figure 3), in which $A$ clearly increases with decreasing wind speed. By grouping values into air-speed bins to reduce sampling effects, the mean value of $A_{\text {eff }}$ in each bin was derived, together with confidence ranges of two standard errors on the means.

A power-law relationship between psychrometer coefficient and wind speed has previously been assumed, e.g. in work concerning the Assmann psychrometer by Svensson (Spencer-Gregory and Rourke, 1957), but such a parameterisation does not fully represent the behaviour because of a discontinuity when the ventilation speed approaches zero. Instead a model for the variation in $A_{\text {eff }}$ with ventilation speed $u$ of the form

$$
A_{\text {eff }}(u)=A_{\infty}+A_{\mathrm{c}} \exp \left(-u / u_{\text {min }}\right)
$$

is adopted for analysis of the laboratory experiment data, which provides a finite value of $A_{\text {eff }}$ when the air speed $u$ is zero. Furthermore, physical interpretation can be given to the different coefficients since $A_{\infty}$ is effectively the air-speed-independent psychrometer coefficient under good ventilation, $A_{\mathrm{c}}$ represents the maximum correction increment required at zero air speed and $u_{\min }$ represents the air speed at which the 
correction required has fallen to $1 / e(\sim 63 \%)$ of that required at zero wind speed. Hence, from the usual exponential response considerations, a well ventilated asymptotic air speed of $u_{\infty} \sim 3 u_{\min }$ can be assumed (i.e. when about $95 \%$ of the exponential change has occurred), above which ventilation speed just the asymptotic value $A_{\infty}$ can be applied.

The binned mean values were used to fit Equation (5) to the data from Figure 3, with equal weightings given to each of the mean values. The fit passes through the confidence limits on the means, yielding $A_{\infty}=(0.68 \pm$ $0.02) \times 10^{-3} \mathrm{~K}^{-1}, A_{\mathrm{c}}=(0.45 \pm 0.02) \times 10^{-3} \mathrm{~K}^{-1}$ and $u_{\min }=(0.26 \pm 0.04) \mathrm{ms}^{-1}$.

\section{(b) Field experiment}

A field experiment extended the laboratory study to a psychrometer operating in a standard meteorological screen under ambient conditions during days 70 to 353 in 2010. The measurements were restricted to temperatures above $5^{\circ} \mathrm{C}$ to avoid complications associated with freezing. (The characteristics of the unusual circumstances when a wet bulb is actually freezing are briefly discussed in the appendix.) Overall, this yielded 6816 hourly values, with a maximum temperature of $T_{\mathrm{dry}}=27.7^{\circ} \mathrm{C}$.

Figure 4 shows a comparison between the hourly values of $R H_{\mathrm{p}}$ and $R H_{\mathrm{r}}$ determined during the experiment. The values plotted were selected for $R H_{\mathrm{r}}<90 \%$, to obtain the best accuracy from the RH reference probe. The data cluster around the 1:1 line, which marks the exact correspondence between the two RH measurements. The mean difference between the $R H_{\mathrm{p}}$ and $R H_{\mathrm{r}}$ measurements $\left(R H_{\mathrm{p}}-R H_{\mathrm{r}}\right)$ is $1.2 \%$, but there is also a noticeable tendency for the psychrometer to record some values for air apparently much moister than that determined by the probe. Specifically, $10 \%$ of the psychrometer RH values have a "moist bias" of $2.8 \% \mathrm{RH}$ or greater over the reference probe. This could be associated with either an anomalously small wet-bulb depression such as from a poorly-operating wick, or resulting from the standard screen psychrometer coefficient assumed $\left(0.8 \times 10^{-3} \mathrm{~K}^{-1}\right)$ being smaller than the effective value required for the measurement circumstances concerned. Rather than assuming the default constant screen psychrometer

This is a preprint of an article accepted (November 2011) for publication in Quarterly Journal of the Royal Meteorological Society Copyright @2011,2012 Royal 
coefficient, the simultaneous dry-bulb and wet-bulb temperature measurements with $R H_{\mathrm{r}}$ allow an effective screen psychrometer coefficient $A_{\mathrm{s}}$ to be determined; using Equations 2 and 4.

Hourly averages of $A_{\text {eff }}$ were calculated, and plotted against the wind speed measured at $2 \mathrm{~m}\left(u_{2}\right)$; Figure 5. Since the sampling is not uniform across the range of wind speeds, the values were binned by wind speed, and then the median value of $A_{\text {eff }}$ in each wind-speed bin derived. These median values were used for the fit, with equal weightings given to each of the median values. Confidence ranges on the median values were also derived as the equivalent of two standard errors on each median (but representing the standard deviation as the inter-quartile range / 1.349 in each bin to allow for the non-normal distribution), which reflects the number of measurements in the different bins.

\section{(c) Applying the model}

The fitted model for $A_{\text {eff }}(u)$ can be used to correct the relative humidity derived from the psychrometer, by allowing the psychrometer coefficient to vary. In this case the corrected psychrometer relative humidity, $R H_{\mathrm{pc}}$ is given by

$$
R H_{\mathrm{pc}}=\frac{100}{e_{\mathrm{s}}\left(T_{\mathrm{dry}}\right)} \boldsymbol{e}\left(T_{\mathrm{wet}}\right)-A_{\mathrm{s}}(u) p\left(T_{\mathrm{dry}}-T_{\mathrm{wet}}\right)
$$

derived from Equations (1) and (2). Equation (6) was used to calculate corrected RH values, using data from the experiment's screen for (i) all hourly values, and (ii) only 0900 UTC measurements.

Figure 6 shows histograms of the differences between the RH from the psychrometer and capacitative probe, with and without the wind speed correction applied. In Figure 6(a), all the hourly values (as presented in Figures 4 and 5) are used (mean error reduces from 1.2 to $0.4 \%$ ). The uncorrected RH values show a long tail of large differences (when the psychrometer RH is greater than that of the reference probe), originally apparent as a bias in Figure 4. Applying the wind-speed correction (Equation 6) greatly reduces both the

This is a preprint of an article accepted (November 2011) for publication in Quarterly Journal of the Royal Meteorological Society Copyright @2011,2012 Royal 
spread of the values (inter-quartile range from 2.0 to $0.8 \%$ ), and the effect of the tail of the distribution (upper decile from 2.8 to $1.5 \%$ ).

Figure 6(b) shows the particular values determined at 0900 UTC only, which is when the regular manual climatological-station observations are made (mean error reduces from 1.0 to $0.1 \%$ ). The effect on the 0900 UTC measurements depends on the wind-speed properties of the site at 0900 UTC, which, for Reading, has about $20 \%$ of $u_{2}$ values below $1 \mathrm{~ms}^{-1}$ (Harrison, 2010), within the range for which the value of $u_{\infty}$ derived indicates psychrometer corrections will be beneficial. The spread of the results is reduced (inter-quartile range from 2.4 to $0.5 \%$ ) and the long tail of increased $\mathrm{RH}$ psychrometer data is diminished (upper decile from 7.3 to $0.7 \%$ ). The effects on the 0900 UTC and hourly distributions are similar, in that the errors and spread are both reduced.

In summary, the well ventilated asymptotic value of psychrometer coefficient agree closely, with $A_{\infty}=$ $(0.68 \pm 0.02) \times 10^{-3} \mathrm{~K}^{-1}$ and $(0.74 \pm 0.02) \times 10^{-3} \mathrm{~K}^{-1}$ for laboratory and field experiments respectively. The zero wind-speed psychrometer coefficient (i.e. $A(u=0)=A_{\infty}+A_{\mathrm{c}}$ ) for the laboratory and field experiments agree within experimental uncertainty, i.e. $A(u=0)=(1.13 \pm 0.04) \times 10^{-3} \mathrm{~K}^{-1}$ and $A(u=0)=(1.08 \pm 0.04)$ $\times 10^{-3} \mathrm{~K}^{-1}$ respectively. The difference between the laboratory experiment's asymptotic wind-speed $u_{\infty}$ below $1 \mathrm{~ms}^{-1}$ and the field experiment's $u_{\infty}$ above $3 \mathrm{~ms}^{-1}$ arises because it is the local wind speed which is measured in the field experiment (as is conventionally determined meteorologically), rather than the withinscreen ventilation received by the psychrometer, which is smaller (Keil, 1996).

This is a preprint of an article accepted (November 2011) for publication in Quarterly Journal of the Royal Meteorological Society Copyright @2011,2012 Royal Meteorological Society 


\section{Comparisons with climatological station data}

To consider whether the similar effects found in the laboratory and field experiment can be expected more generally, humidity measurements were analysed from a different site.

For this comparison, daily screen measurements (including a psychrometer formed from liquid-in-glass thermometers) were obtained from the Met Office Research Unit at Cardington, Bedfordshire, UK (Met Office, 2011), for weekdays between $1^{\text {st }}$ January 2006 and $30^{\text {th }}$ November 2009. Cardington's data was chosen since it provides reliable reference measurements of temperature and humidity determined by a further HMP45A capacitative humidity probe, operated outside the pyschrometer screen on a 1.2-metre mast; although in rather less-controlled conditions than the Reading field experiment.

Possible effects of separation of the reference and screen measurements were assessed first. The daily 0900 UTC screen dry-bulb temperatures were compared with the simultaneous reference PRT measurement $\left(T_{\mathrm{r}}\right)$ on the 1.2-metre mast. The correlation coefficient was $r=0.9967$, and the mean bias was $+0.03 \mathrm{~K}$ (mean absolute difference $0.24 \mathrm{~K}$ ), indicating little bias in the sampling of both sets of instruments.

Following the same procedure (i.e. Equation 4), the screen psychrometer coefficient $A_{\mathrm{s}}$ was derived and plotted against wind speed (Figure 7). The data were again binned by wind speed to eliminate the effects of sampling and provide a measure of spread. From this, the increase of $A_{\mathrm{s}}$ at low wind speeds is again clear and it is also apparent that the analytical relationship obtained in Figure 5 passes through the majority of the confidence intervals. Overall, correcting these data for ventilation (Equation 6) improves the psychrometer measurement by $0.6 \%$ RH (from $3.3 \%$ moist bias in RH to $2.7 \%$ ). 


\section{Conclusion}

The general applicability of the correction depends on the physical condition of the psychrometer considered, and its conformity to standardised operating procedures such as employing pure water and regularly fitting fresh wet bulb wicks. The wooden large thermometer screen considered in the experiment was of standard size and conventional double-louvre design from which many screens show only minor variations, but for substantially different screen constructions (Parker, 1994) air flow characteristics could be fundamentally different.

Applying the wind-speed correction to the psychrometer coefficient is effective in reducing the uncertainty in the relative humidity determined by a screen psychrometer, for 2 -metre wind speeds below $3 \mathrm{~ms}^{-1}$. For both the Reading field experiment and Cardington comparison, this presents an improvement upon the traditional assumption of a wind-speed-independent value. This correction is practicable for data from automatic measurement sites at which wind-speed and psychrometer data are determined simultaneously. Since the ventilation effect on the screen psychrometer coefficient can be appreciable due to the sensitivity evident in Figure 1d, trends in relative humidity derived without such a correction applied may also partially reflect a long-term trend in wind speed at the site considered.

\section{Acknowledgement}

A.G. Lomas and R.J. Wilson maintained the University of Reading Atmospheric Observatory data acquisition system; M.R. Stroud made the regular checks on the thermometer screens throughout the experiments. We thank the UK Meteorological Office (McGregor, J. and Price, J.) and the Natural Environment Research Council's British Atmospheric Data Centre (BADC) for the Cardington data. 


\section{Appendix}

During preparatory experiments for this study, some dry-bulb temperatures below freezing occurred. In persistent freezing conditions, convention requires that the wet bulb should be replaced by an ice bulb (a thermometer coated with a thin layer of ice), and the humidity calculated using the vapour pressure over ice (HMSO, 1982) using a value of $A$ appropriate for an ice bulb $\left(A=0.7 \times 10^{-3} \mathrm{~K}^{-1}\right)$. However, intermediate conditions occasionally exist when the wet bulb is frozen or actually freezing, which need to be identified. These circumstances are evident with continuous recording systems, unlike manual systems which make only infrequent observations. Supercooling is apparent from the subsequent transient behaviour of the wet bulb, and Figure A presents examples. In both examples $T_{\text {dry }}$ had been sub-zero for a prolonged period, after which $T_{\text {wet }}$ transiently increased to become considerably greater than $T_{\text {dry }}$, reaching $\sim 0^{\circ} \mathrm{C}$ before slowly cooling until the wet bulb ultimately became colder than the dry bulb. This is interpreted as the freezing of the wet bulb, by analogy with the very similar temperature changes known during freezing of an isolated supercooled water droplet (e.g. Harrison and Lodge, 1998). During freezing, latent heat is released, causing the ice-water mixture on the wick to warm briefly. When the wet bulb has frozen entirely, no further latent heat is released, and the wet bulb cools in the ambient air to the dry-bulb temperature. It is then effectively a frozen wet bulb - rather than an ice bulb - since there is an unknown quantity of ice associated, and not present as a uniform thin layer as would be the case for an ice bulb.

The frequency of such effects will be site dependent. Analysis of University of Reading Atmospheric Observatory data between 1997 and 2008 showed that transient warmings of the wet bulb of greater than $0.5^{\circ} \mathrm{C}$ above $T_{\text {dry }}$ in a 5-minute period (whilst $T_{\text {dry }}<0^{\circ} \mathrm{C}$ ) occurred 114 times. The median $T_{\text {dry }}$ associated during this was $-0.6^{\circ} \mathrm{C}$ (inter-quartile range $0.7^{\circ} \mathrm{C}$ ), indicating modest supercooling, but some freezing wetbulb events occurred down to $T_{\mathrm{dry}}=-3.5^{\circ} \mathrm{C}$. Naturally, during these freezing wet-bulb circumstances, the psychrometer theory is invalid because of the latent heat release.

This is a preprint of an article accepted (November 2011) for publication in Quarterly Journal of the Royal Meteorological Society Copyright @2011,2012 Royal 


\section{References}

Aitken J. 1921. Thermometer screens. Proc. Roy. Soc. Edinburgh 40:172-181.

Bolton D. 1980. The computation of equivalent potential temperature. Mon. Weather. Rev. 108: 1046-1053. Harrison RG, Lodge BN. 1998. A calorimeter to detect freezing in supercooled water droplets. Rev. Sci. Instrum. 69: 4004-4005.

Harrison RG, Rogers GW. 2006. Fine wire resistance thermometer amplifier for atmospheric measurements. Rev. Sci. Instrum. 77: 116112.

Harrison RG. 2010. Natural ventilation effects on temperatures within Stevenson screens. Quart. J. Roy. Meteorol. Soc. 136: 253-259.

Harrison RG. 2011. Lag-time effects on a naturally ventilated large thermometer screen. Quart. J. Roy. Meteorol. Soc. 137: 402-408.

HMSO. 1982. Handbook of meteorological instruments, Volume 3 (Measurement of humidity). Meteorological Office, 2nd edition, Her Majesty's Stationery Office.

Keil M. 1996. Temperature measurement in Stevenson screens. MSc dissertation, The University of Reading.

Met Office 2009. SPOT-ON Observers Guide. Version 4. Met Office, UK.

Met Office 2011. UK Meteorological Office Cardington, [McGregor, J.; Price, J.], data taken from NCAS British Atmospheric Data Centre, http://badc.nerc.ac.uk/view/badc.nerc.ac.uk_ATOM_dataent_cardington, (accessed 18 August 2011). Murphy J, Sexton D, Jenkins G, Booth B, Brown C, Clark R, Collins M, Harris G, Kendon E, Betts R, Brown S, Boorman P, Howard T, Humphrey K, McCarthy M, McDonald R, Stephens A, Wallace C, Warren R, Wilby R, Wood R. 2009. UK Climate Projections Science Report: Climate change projections. Met Office Hadley Centre: Exeter.

Parker DE. 1994. Effects of changing exposure of thermometers at land stations. Int. J. Clim. 14: 1-31. Spencer-Gregory H, Rourke E. 1957. Hygrometry. Crosby Lockwood and Son, London.

This is a preprint of an article accepted (November 2011) for publication in Quarterly Journal of the Royal Meteorological Society Copyright @2011,2012 Royal Meteorological Society 
Willett KM, Gillett NP, Jones PD, Thorne PW. 2007. Attribution of observed surface humidity changes to anthropogenic influence. Nature 449: 710-712.

WMO. 2006. Guide to Meteorological Instruments and methods of observation. WMO-No.8. World Meteorological Organisation: Geneva.

\section{Figure captions}

\section{Figure 1.}

Screen psychrometer calculations of relative humidity $(\mathrm{RH})$ (a) and (c), showing the range of absolute $\mathrm{RH}$ uncertainty resulting from (a) $\pm 0.2{ }^{\circ} \mathrm{C}$ uncertainty in the wet-bulb temperature depression assuming the standard screen psychrometer coefficient of $0.8 \times 10^{-3} \mathrm{~K}^{-1}$ and from (c) varying the psychrometer coefficient from $1.1 \times 10^{-3} \mathrm{~K}^{-1}$ (poorly ventilated, dotted lines) to $0.7 \times 10^{-3} \mathrm{~K}^{-1}$ (well ventilated, dashed lines) around the standard screen psychrometer coefficient of $0.8 \times 10^{-3} \mathrm{~K}^{-1}$ (thick lines). (b) and (d) show the associated absolute change in RH against dry-bulb temperature and wet-bulb depression for the temperature $(T)$ and wind speed $(u)$ variations respectively.

\section{Figure 2.}

Schematic of the laboratory experiment to determine the effect on a pyschrometer under forced ventilation. Wet and dry bulb thermometers $\left(T_{\text {wet }}\right.$ and $\left.T_{\text {dry }}\right)$ were operated, within a fan-ventilated $920 \mathrm{~mm}$ horizontal cylindrical wind tunnel of $97 \mathrm{~mm}$ diameter tube, at $380 \mathrm{~mm}$ from the inlet. The dew-point temperature $\left(T_{\text {dew }}\right)$ of the incoming air was found using a Mitchell Instruments Series 3000 dew-point meter, and the air speed $U$ measured downstream of the thermometers $(780 \mathrm{~mm}$ from the tube inlet) with a Testo 425 thermal anemometer. 
Figure 3.

Laboratory determination of the psychrometer coefficient, $A_{\text {eff }}\left(N=51\right.$; grey points). Mean values of $A_{\text {eff }}$ (black points) for $0.5 \mathrm{~ms}^{-1}$ wind-speed bins are together with $95 \%$ confidence limits. The fitted relationship is shown (dashed line) from Equation 5, with derived coefficients: $A_{\infty}=(0.68 \pm 0.02) \times 10^{-3} \mathrm{~K}^{-1}, A_{\mathrm{c}}=(0.45$ $\pm 0.02) \times 10^{-3} \mathrm{~K}^{-1}$ and $u_{\min }=(0.26 \pm 0.04) \mathrm{ms}^{-1}$, where the uncertainties in each coefficient represent two standard errors.

\section{Figure 4.}

Hourly averages (6816 values from days 70 to 353 inclusive, in 2010, at the University of Reading Atmospheric Observatory) of RH determined by a capacitative reference probe compared with those from a screen psychrometer (assuming standard psychrometer coefficient $A_{\mathrm{s}}=0.8 \times 10^{-3} \mathrm{~K}^{-1}$ ), for values obtained in unsaturated air $(\mathrm{RH}<90 \%)$ with temperatures above $5^{\circ} \mathrm{C}$. The dashed line marks the $1: 1$ relationship.

\section{Figure 5.}

Effective screen psychrometer coefficient $A_{\mathrm{s}}$ calculated from hourly values of $\mathrm{RH}$ from the screen psychrometer, against 2-metre wind speed (grey points). Median values of $A_{\mathrm{s}}$ (black points) have been found by grouping the data into wind-speed bins of width $0.3 \mathrm{~ms}^{-1}$ are also shown with $95 \%$ confidence limits marked. The fitted relationship is shown (dashed line) from Equation 5: coefficients are $A_{\infty}=(0.74 \pm$ $0.02) \times 10^{-3} \mathrm{~K}^{-1}, A_{\mathrm{c}}=(0.34 \pm 0.02) \times 10^{-3} \mathrm{~K}^{-1}$ and $u_{\min }=(1.30 \pm 0.22) \mathrm{ms}^{-1}$, where the uncertainties in each coefficient represent two standard errors. 
Figure 6.

Histograms of hourly differences in $\mathrm{RH}$ for the psychrometer and capacitative sensors (i.e. $R H_{\mathrm{p}}-R H_{\mathrm{r}}$ ), using the standard screen psychrometer coefficient $A$ (grey bars) and wind-speed-corrected psychrometer coefficient $A_{\mathrm{s}}\left(u_{2}\right)$ (black bars). The histograms are for (a) all hourly data and (b) 5-min average data at 0900 UTC only.

\section{Figure 7.}

Effective screen psychrometer coefficient $A_{\mathrm{s}}$ calculated for the Met Office Research Unit at Cardington (Bedfordshire, UK) using data from $1^{\text {st }}$ January 2006 to $30^{\text {th }}$ November 2009. Grey points are effective screen psychrometer coefficient $\left(A_{\mathrm{s}}\right)$, calculated from hour-average vapour pressure (using $R H_{\mathrm{r}}$ and $T_{\mathrm{r}}$ ) at 0900 UTC from the 1.2-metre mast and from the screen psychrometer measurement $\left(T_{\text {dry }}\right.$ and $\left.T_{\text {wet }}\right)$ at 0900 UTC. The 2-metre wind speed was estimated by reducing the 10 -metre measurement by $30 \%$, according to Met Office (2009). Mean values of $A_{\mathrm{s}}$ (black points) have been found by grouping the data into wind-speed bins of width $0.5 \mathrm{~ms}^{-1}$, with $95 \%$ confidence limits marked. The curve (dashed line) is the fitted relationship found in Figure 5.

\section{Figure A.}

Transient temperature changes in the wet-bulb temperature (thick black line) associated with sub-zero drybulb temperatures (dashed line), with the probe relative humidity also shown (thin black line), for (a) day 331 and (b) day 339 of 2010, at University of Reading Atmospheric Observatory. 
(a) RH (T variation)

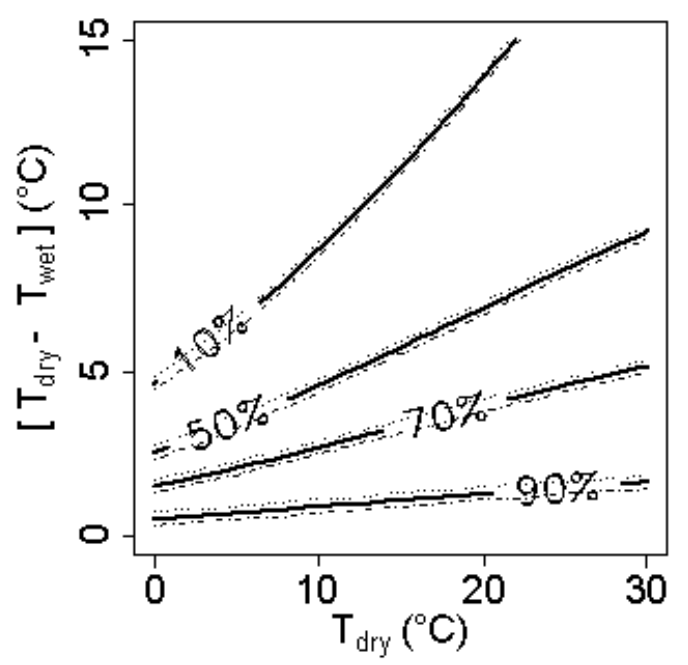

(c) RH (u variation)

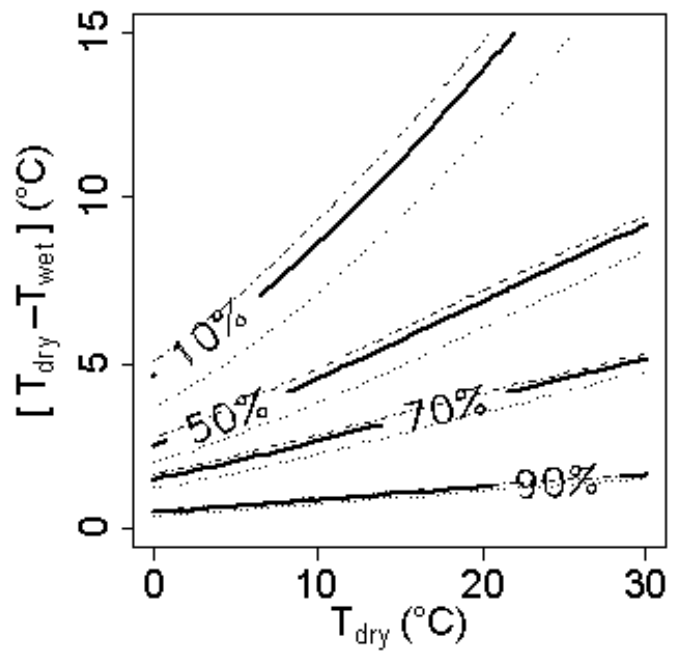

(b) RH sensitivity (T)

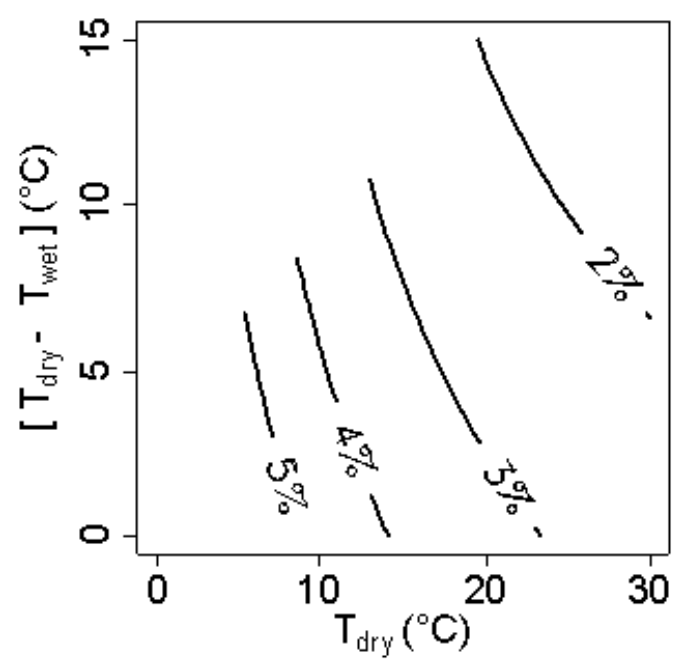

(d) RH sensitivity (u)

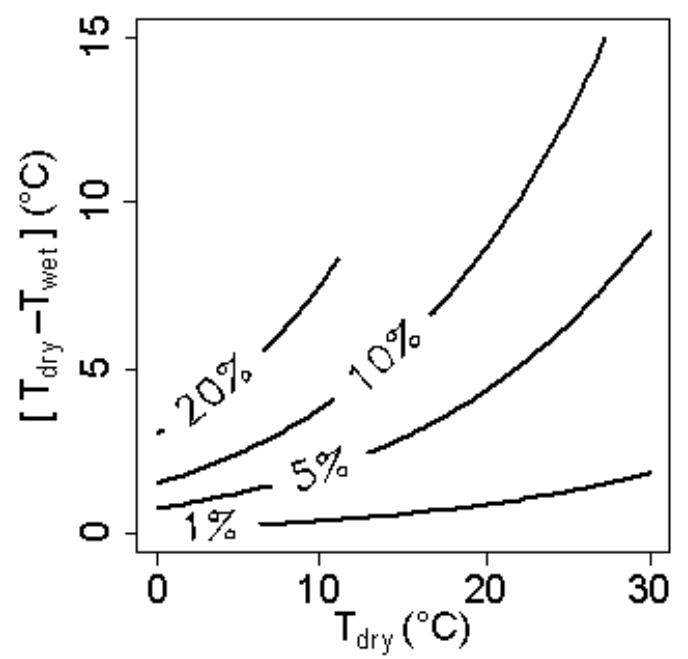




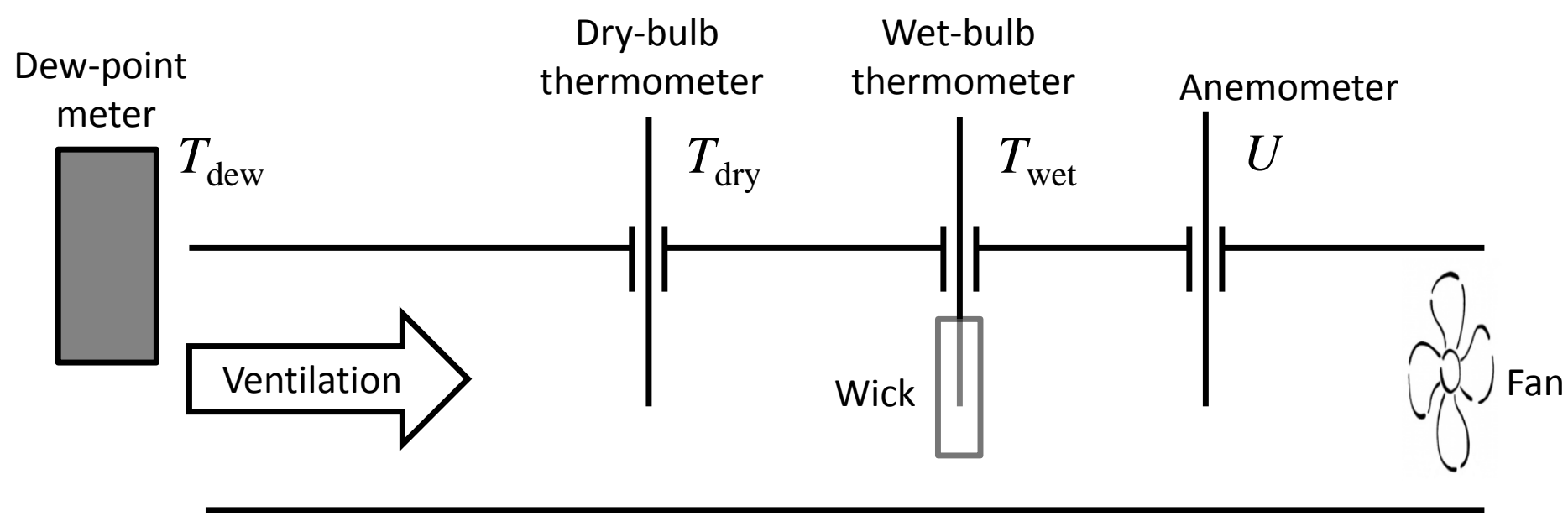




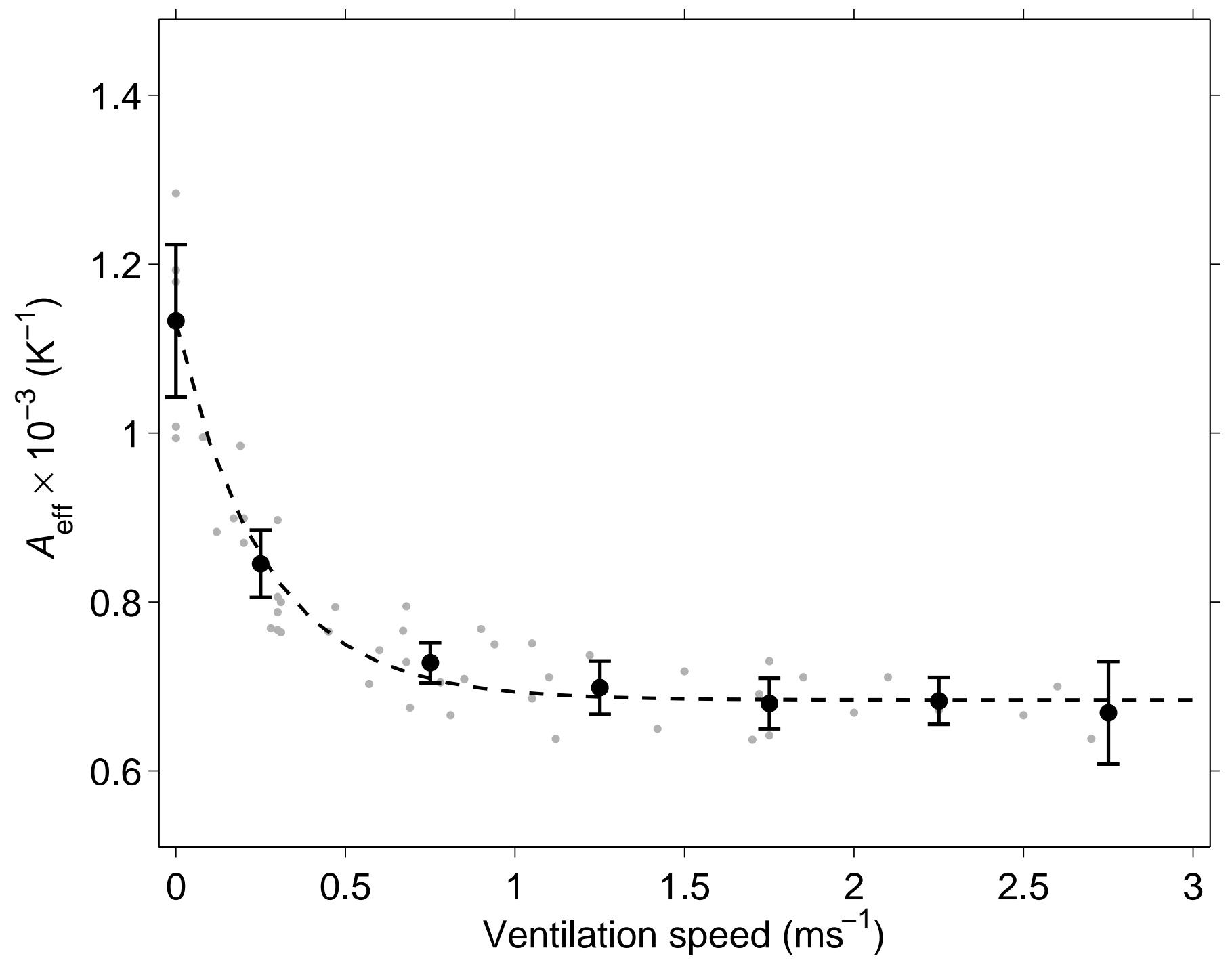




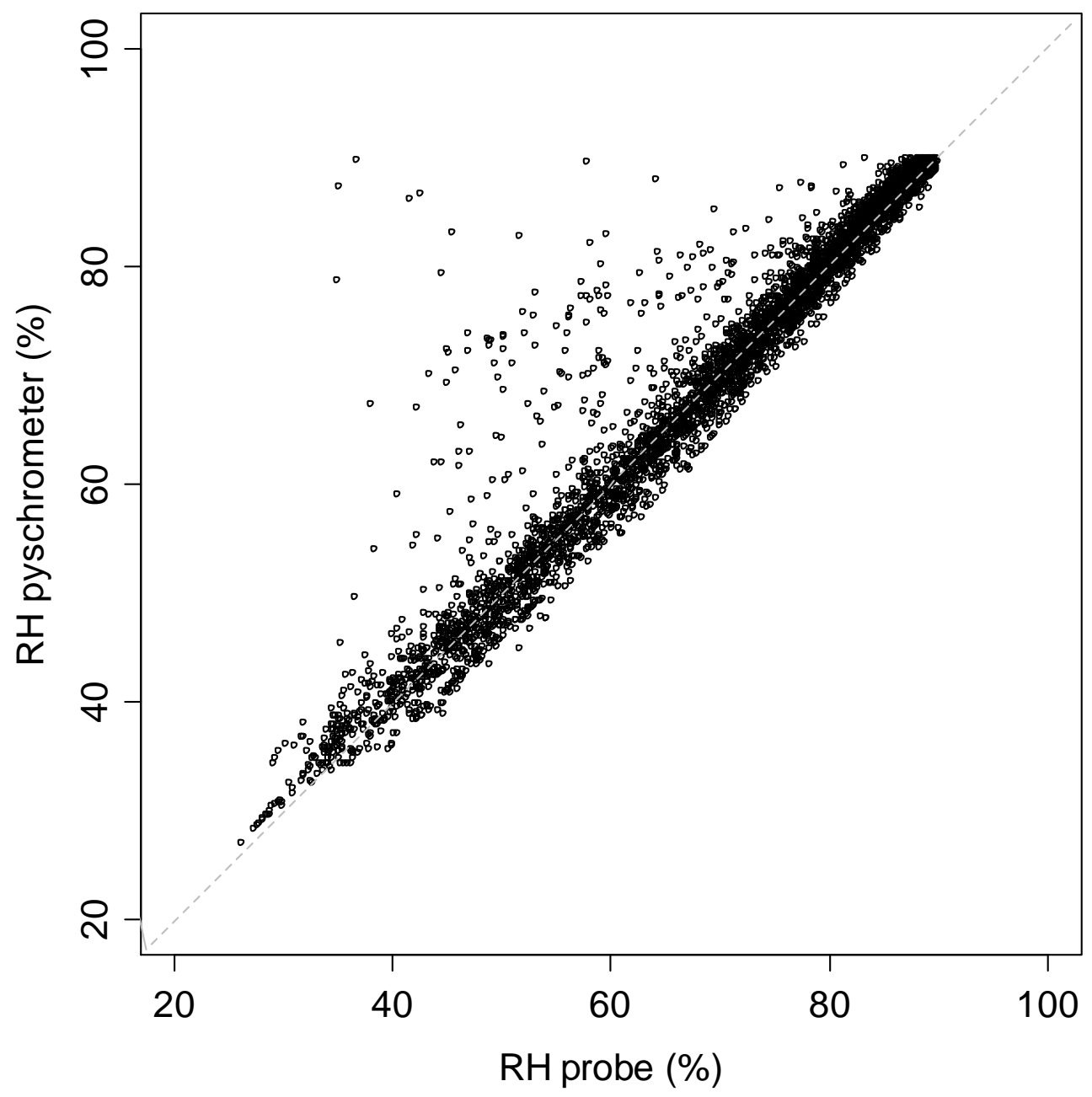




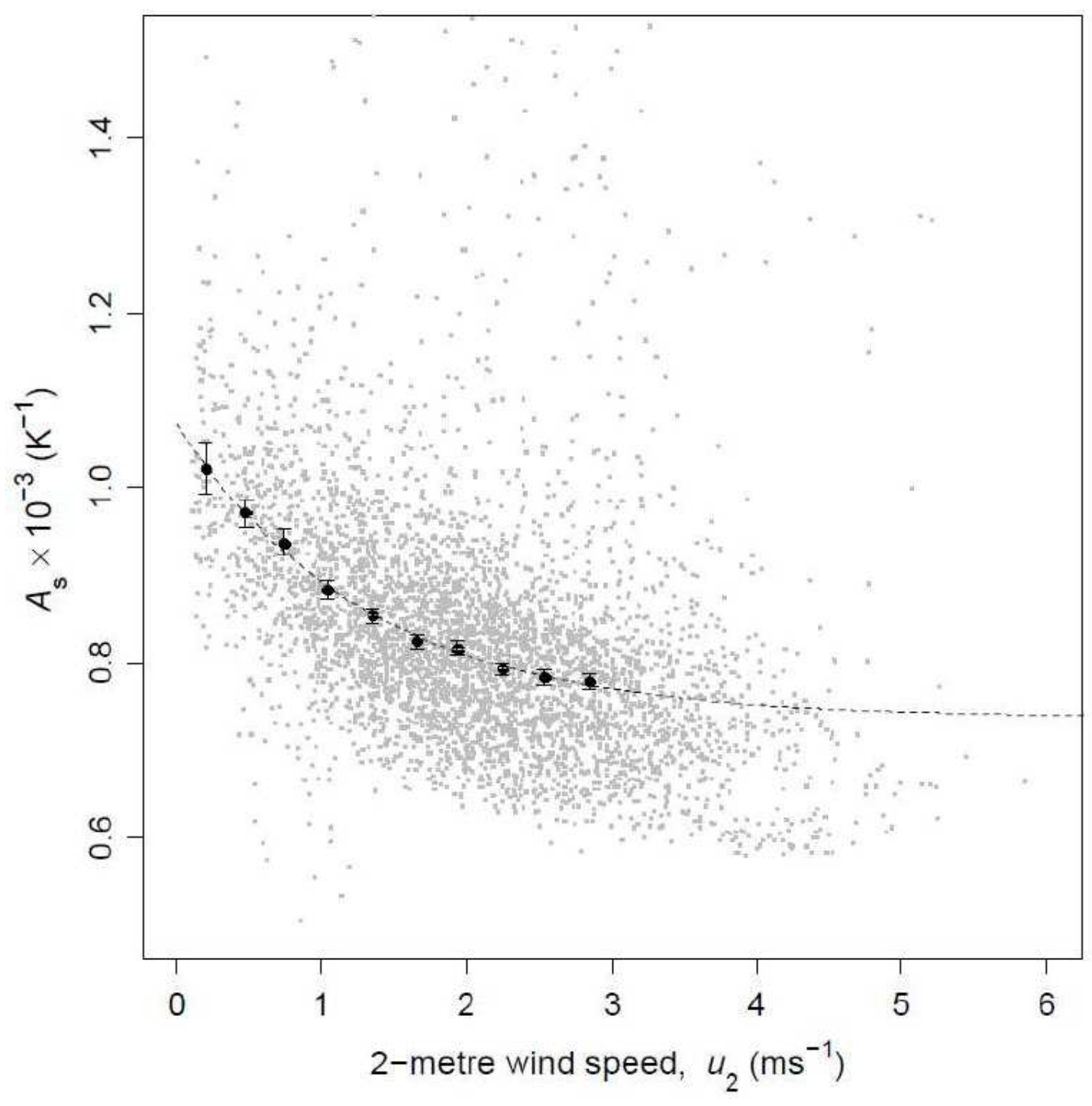


(a)

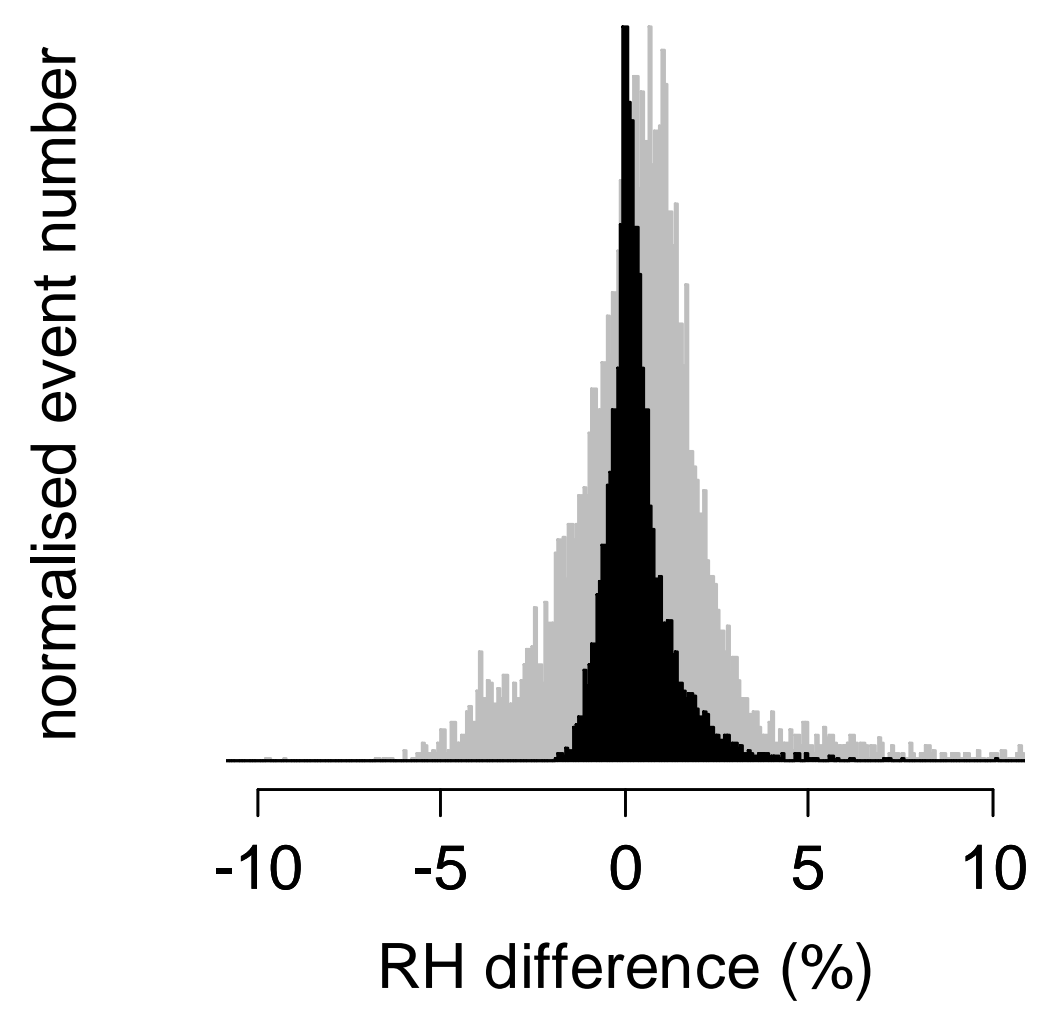

(b)

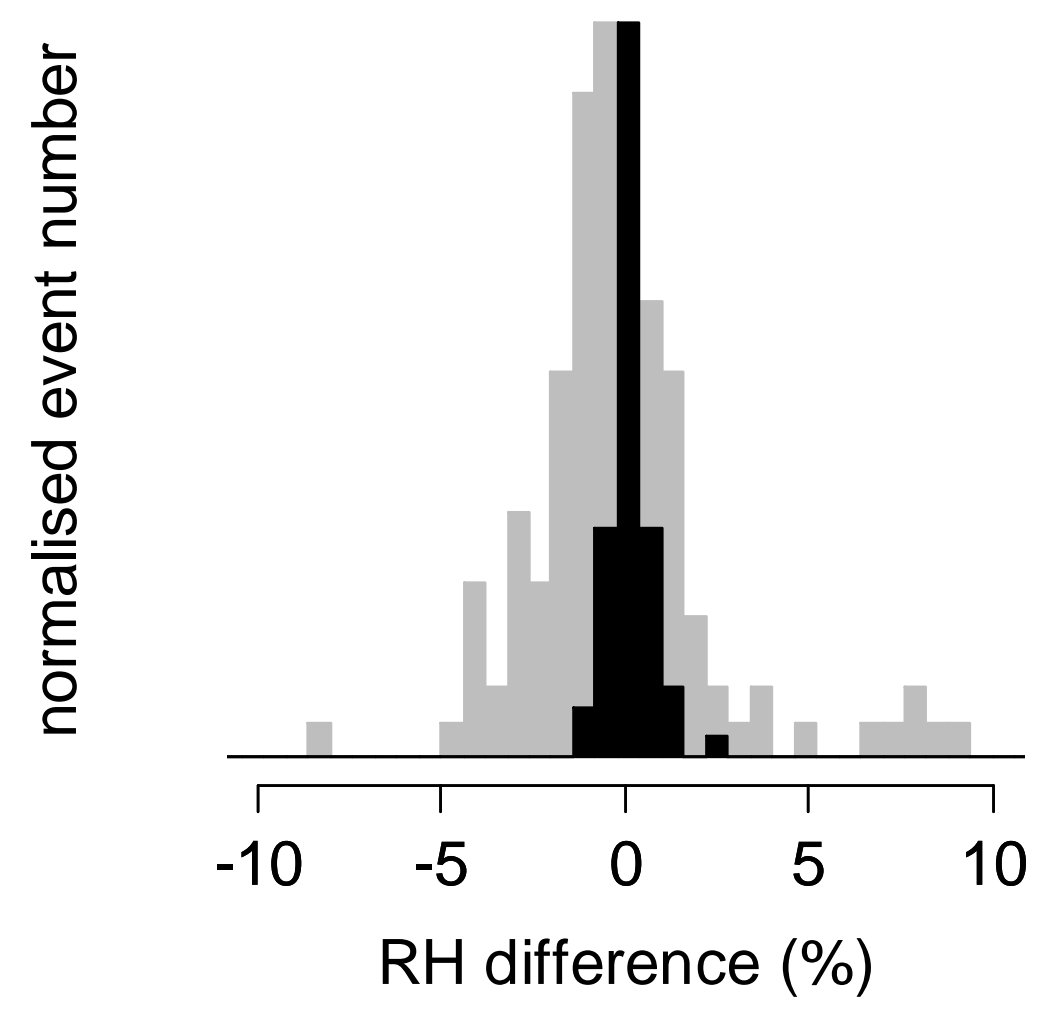




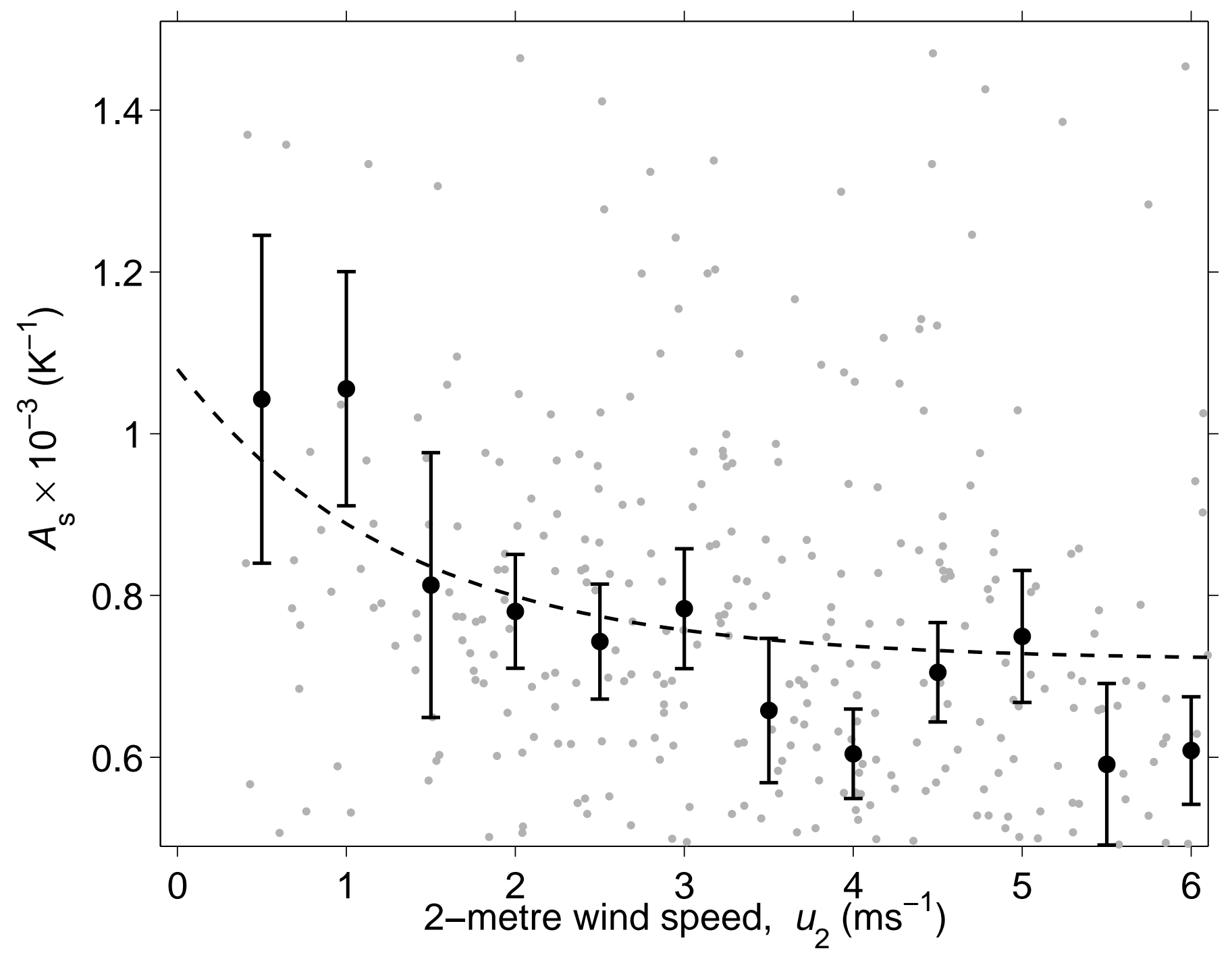


(a)

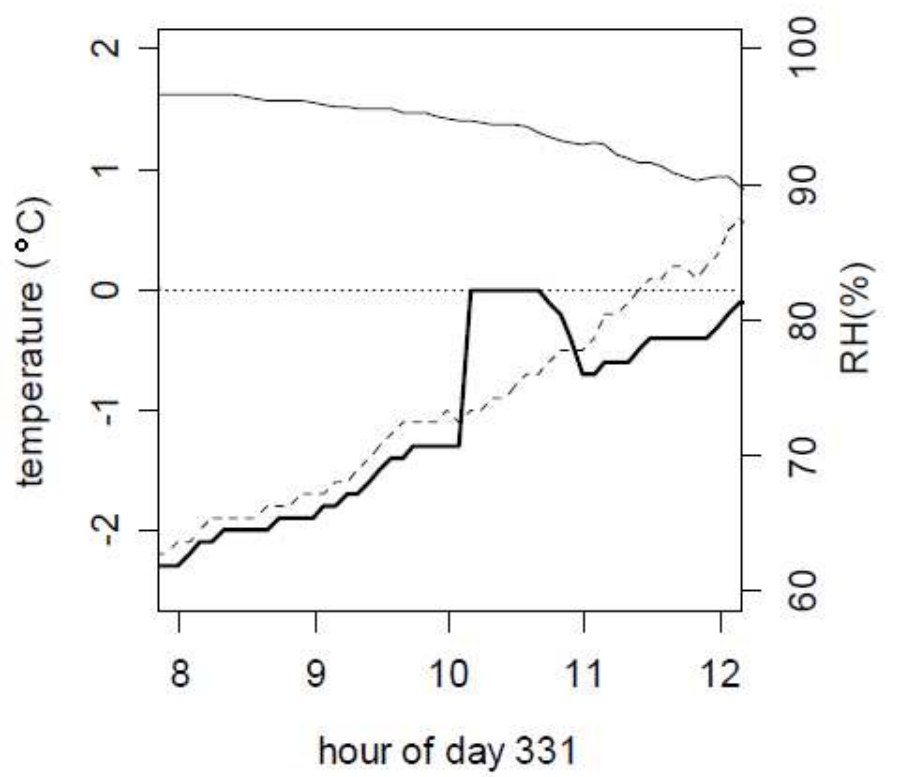

(b)

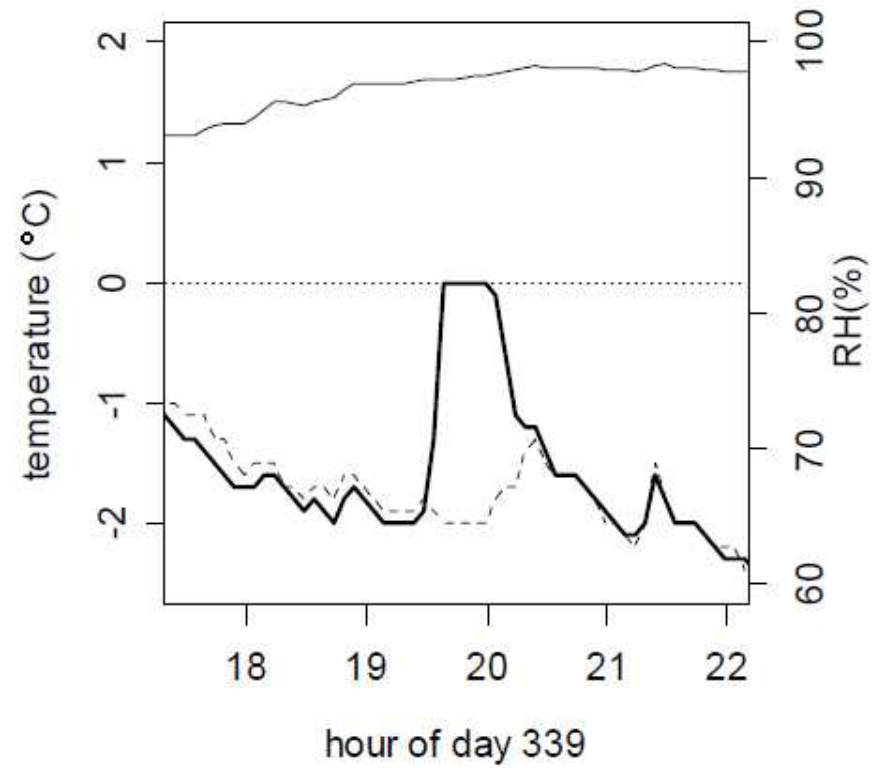

